\title{
DEVELOPMENT OF BASIC PHYSICAL QUALITIES, ESSENTIAL CONDITION FOR CREATING A COMPETITIVE PHYSICAL CAPACITY
}

\author{
Robert STÄNCIULESCU \\ rstanciulescu@armyacademy.ro \\ “NICOLAE BĂLCESCU” LAND FORCES ACADEMY, SIBIU, ROMANIA
}

\begin{abstract}
Physical qualities are crucial elements constituting the training process, along with the technical, psychological or tactical training.

The more the physical qualities, speed, agility, endurance and strength are developed, the greater the major functions of the body, especially breathing and circulation have a higher activity potential and the body appropriates easier and better a wide range of basic and practical-applied physical skills.

In the modern conception, providing superior indices for physical skills development has become a prerequisite to achieving superior performance, therefore it represents the priority number one of specialists in identifying increasingly more sophisticated methods to ensure efficiency.
\end{abstract}

\section{KEYWORDS:}

Effort, intensity, volume, complexity, procedures and methods

\section{Introduction}

Maintaining and developing the general and specific body movement is a prime objective, perhaps the most important of physical activities.
The level of development of basic physical skills, speed, agility, endurance and strength is essential for obtaining performance in physical education and sport contributes beneficially to the successful performance of the professional 
activity of certain categories of staff. We may consider that the development of physical skills affects directly the activity and improvement of the main functions of the body, the increase of effort capacity, the development of the spirit of observation, imagination, inventive thinking, tenacity, perseverance and courage.

It is extremely important to know that the development of physical skills is based on making some efforts which need to be well designed and rigorously conducted, whereas the scope of their manifestations in the body is quite complex.

Thus, besides the muscular or osteoarticular effort, the body also makes efforts of the nervous system, achieving high performance representing not only physical tasks, but also moral, volitional activities, such as willpower, fortitude and self-confidence.

Benefits resulting from a performance training process are huge, thus, finding new forms and methods of training to ensure increasingly better results is a constant concern of professionals in the field.

From this point of view, we can appreciate that the physical qualities developed and maintained as close to the limit of biological adaptability require a target-oriented instructive-educational process, organized and conducted scientifically.

\section{Ways to Develop Physical Qualities}

Energy resources mobilized for the development of physical skills is channelled, as noted above, in a general effort of the body aimed at, among others, the development of physical skills. Dosage of the effort needed to attain the objectives is done with great attention both by performers and by specialized professionals, taking into account some variables of which the most important are the essential characteristics of effort, namely the volume, intensity and complexity.

When referring to the level of effort in which the osteoarticular and muscular system is involved, thus to the physical strain of the organism, we can estimate the volume as being the amount of mechanical work obtained in a unit of time. Hence it results the effort's density, which is expressed by the number of activities in a unit of time (repetitions, distances etc.).

The intensity which it is acted upon the body with when performing certain actions, with clearly defined goals, for the development of a physical quality also means the intensity of the effort. It can be expressed as a percentage and represents a certain part of the body's ability to perform various physical actions (e.g. I $60 \%$, I 3/4).

The third feature of effort, namely complexity, refers to the way in which all components that contribute to performing a physical action are associated. How these elements are used, largely depends on achieving the set goals.

In Figure no. 1 there are presented the effort's characteristics:

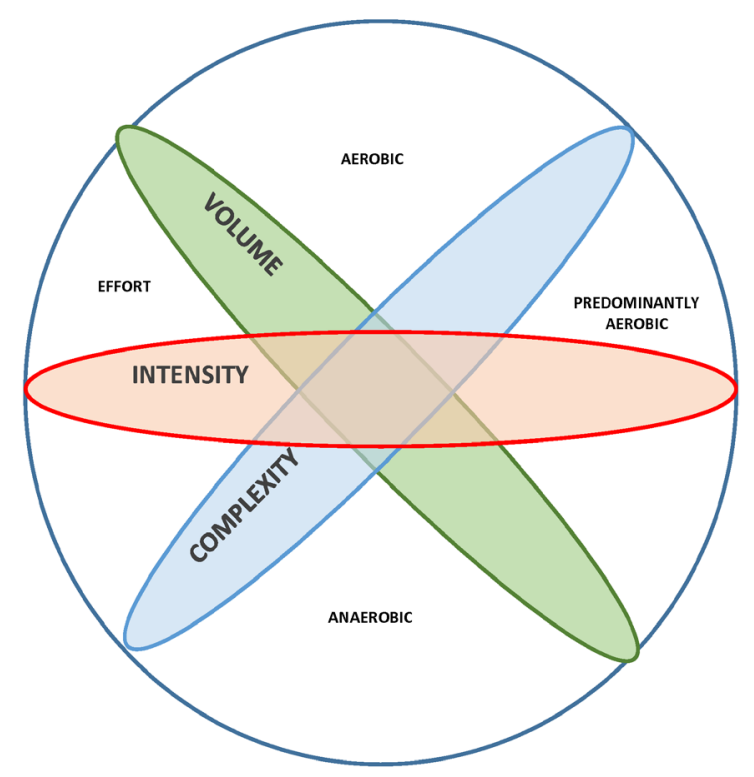

Figure no. 1 Effort's characteristics

It is extremely important to know that during the performance of certain muscle actions, muscle contractions are the result of chemical processes and their performance requires a high consumption of oxygen. Certainly, the body has the capacity to provide the oxygen needed to replenish the energetic substrate and, depending on the quantity it can ensure over time, two types of effort can be differentiated: efforts 
predominantly aerobic, which are characterized by an instant recovery of the energetic substrate, i.e. during the physical act the oxygen supply needed for body recovery is also being performed. Here we may speak of a low-intensity of the effort. Predominantly anaerobic efforts are characterized by high and very high intensity. The body fails to provide the necessary oxygen for the recovery of the energetic substrate, this being done in time, thereby the recovery of the body needs a longer time to ensure the required supply of oxygen.
These are issues that need to be taken into account to a great extent with the implementation of specific methods for the development of physical skills.

Speed and strength development is done by driving methods which involve a predominantly ANAEROBIC effort and of endurance and mobility, through methods that involve the manifestation of a predominantly AEROBIC effort (Siclovan, 1999).

In Figure no. 2 the characteristics of these two types of effort are presented.

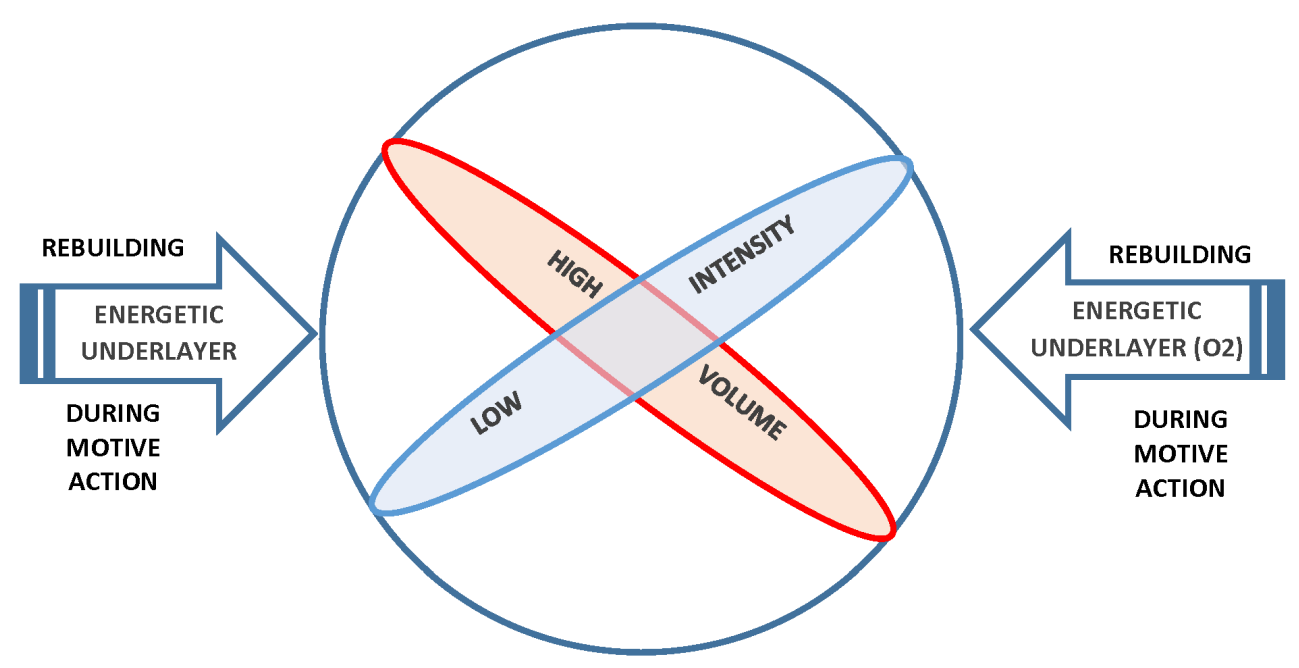

Aerobic effort

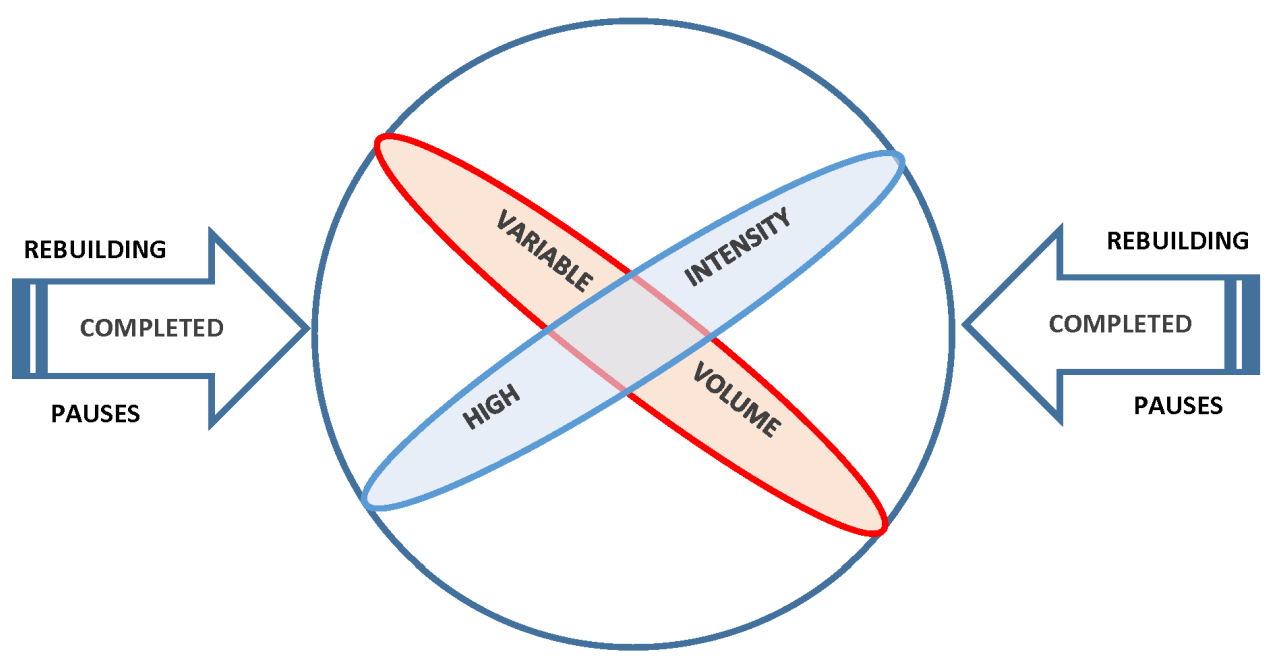

Anaerobic effort

Figure no. 2 Characteristics of the aerobic and anaerobic effort 


\subsection{Methodical Processes of Developing Speed}

Ways of acting and methods used to speed development are endless, because both the features of sports disciplines for which it is acted, and the morphofunctional peculiarities of the body must be taken into account. This is a physical quality of great finesse.

Domain experts consider that the place for developing speed in the lesson is immediately after the introduction sequence, more precisely after the selective influence of the musculoskeletal system as the body is rested and stimuli reception can be beneficial.

Many specialists range speed development methods depending on their manifestations.

Thus, we can talk about the following methods and ways of operation (Dragnea, 1989):

1. For the development of the reaction rate: the repetition method, the fractional method, the sensory method.

2. For the development of execution speed: the repetition method, the fractional method, the integrated method.

3. For the development of repetition speed: the alternative method and the repetition method.

In general, we can enumerate the following methods and processes:

$\checkmark$ physical and practical-applied skills execution in various tempos of execution;

$\checkmark$ alternating the execution of different physical skills and practical and applied physical abilities in increased tempos;

$\checkmark$ performing physical and practicalapplied skills and abilities, by gradually increasing the tempo until reaching maximum speed.

Regardless of the methodical procedures used it is necessary to take into account the following aspects:

$\checkmark$ performance of movements at full speed is the best way to educate (develop) speed; $\checkmark$ repetition of movements is performed only after the body was reestablished in terms of recovery (it is known that training effects are felt only when acting on a rested body);

$\checkmark$ movements and exercises used should be designed so as to ensure maximum speed use (where this process this used at the end);

$\checkmark$ the development of other physical qualities will be had in view together with the development of speed.

\subsection{Methodical Procedures to}

\section{Develop Force}

As with the physical quality - speed, there is an extremely large number of methodological procedures by which, according to the forms of the force or the sports discipline for whose development is sought, specific objectives can be achieved.

In the paper Teoria antrenamentului (The Theory of Training), T. Haree divides specific exercises for the development of force as follows:

$\checkmark$ contest exercises (customizing, we can call this type of exercises also for evaluation, if we were to consider the performance verification for different sports disciplines). At this type of exercises the conditions used for evaluation or slightly more difficult conditions are employed.

$\checkmark$ specific exercises where other materials are used than those specific to the sports disciplines for which it is exercised;

$\checkmark$ exercises for general force development, certainly with a generalized character.

We will further present a set of methods, which over time have ensured effectiveness of training programs for developing this physical quality.

According to Ion Siclovan, in his paper Theory of Physical Education and Sport, there are two categories of processes which develop both muscle mass and expansion.

- The process of making movements involving intense and rapid muscle contractions. This process does not refer to increasing muscle mass but to the muscle's 
ability to contract in a short time. It is used especially in disciplines that do not need muscle mass but strength in speed mode.

- Isometric process, where force development is ensured by pushing a static resistance, situation where muscle length is not changed.

- Weight lifter method is another method through which maximum force development is achieved. The reference element in this method is the progressive increase of the load.

- POWER-TRAINING method - is a method used to develop force in speed mode. In this method, the main elements concern (Mogoş \& Mitra, 1980):

- size of the load;

- increasing the number of repetitions;

- increasing the execution speed.

- The circuit process - aims to develop the main muscle groups. In this method it is recommended that:

- exercises do not require high skill indices;

- the difficulty of exercises increases gradually;

- exercises do not have a high degree of difficulty.

Certainly, regardless of the methods used in specific activities for force development, the following guidelines must be taken into account:

- correct training of muscles for the effort that will be made;

- low energy consumption and maximum performance;

- use of breaks to restore the body's ability.

\subsection{Methodical Processes to Develop}

\section{Resistance}

The methods and specific procedures for the development of resistance are very closely related to three important components of effort, namely the duration of the exercise, its intensity and recovery of the body.

To all these, as for the processes used to develop the other physical qualities, particular characteristics of the sports disciplines are added, and even of the distances where evaluations are made.

The main methodical processes of developing resistance are (Dragnea \& Mate-Teodorescu, 2002):

- The process of repeating efforts at uniform intensity. At this process, the aerobic effort prevails, i.e. where the restoration of oxygen substrate necessary to the body is made while operating the exercise. In this process, which is characterized both by intensity and volume, there are not significant changes, but in the variation of volume. Intensities of the effort are constant.

- The process of repeating efforts by changing intensity. At this process, the anaerobic effort prevails. The intensities are either increased progressively or variable, from one physical action to another. Certainly, the volume is quite low having a ratio of reversed proportionality, i.e. low volume, high intensity, as opposed to the process of repeating efforts at uniform intensities where volume is high and intensity is constant.

- The process of variable efforts which is characterized both by volume and intensity variation. This process is extremely complex, its use maintaining the knowledge of morphological and functional characteristics of the body, its restoring possibilities and the capacity of individual effort. The advantage of this type of training materializes, beside the fact that it can be used in any field conditions or weather conditions, improves cardio-respiratory function and is considered a process with increased efficiency in developing the qualities of will and mental strength of students.

\subsection{Methodical Processes of Skill} Development

As we have previously showed, skill, through its ways of operation, is represented by balance, space and temporal orientation, flexibility, amplitude or muscle relaxation.

Methodical processes of skill development are very many, ultimately depending on the teachers' or trainers' skill 
and on the morphofunctional characteristics of athletes or the level of development of other physical qualities. Undoubtedly, in order to establish specific procedures, the following specific issues should be taken into consideration: developing skill is performed at the beginning of the physical education lesson (in the first part of the sequence of instruction) or during the preparation of the body for effort through specific exercises on a rested body; compliance with rest intervals large enough to allow the body to cope with the demands imposed; it will be taken into account that the workload must be low and the exercises used are as many as possible, more challenging and more relaxing at the same time.

According to Gheorghe Mitrea and Alecsandru Mogoş, in Metodica Educatiei Fizice Scolare (School Physical Education Methodology), 1980, the ways and means for skill development are divided into two main groups:

- The first group includes all the acting systems used in the instructive and educational process related to learning; acquiring basic physical skills and abilities (those aimed at knowing the fundamental characteristics of movement), the practicalapplied or basic physical skills (walking, running, jumping);

- The second group includes the activities designed to enhance the ability to apply physical knowledge, skills and abilities organized into various games or activities that include competition.

According to some authors the most effective methodical processes are:

- execution of exercises under various conditions to perform them;

- carrying out exercises by changing methods of execution;

- execution of exercises under saddled conditions;

- execution of exercises with other parts of the body or on the unskillful part;

- changing the speed of executing exercises;

- learning exercises according to the principles from simple to complex, from easy to difficult, from the known to the unknown, by developing and executing them under high speed tempo.

\section{Conclusions}

The degree of developing basic physical skills is essential to strengthening and improving basic physical and practicalapplied skills and abilities and has great influence in conditioning the health of the body.

To be most effective specialists in the field should take into account the following specific issues:

- planning methods and means of actuation to develop physical skills requires careful planning and a thorough knowledge of body characteristics of the persons involved in the development process;

- conducting a thorough and careful coordination of the relationship volumeintensity reported to the physical quality on which it is operated;

- particular attention will be given to the principles: from simple to complex and from easy to difficult;

- the results obtained during training will be well managed and the application of the most effective exercises for developing a specific physical skill will be considered;

- while developing basic physical skills, developing qualities of will, courage, perseverance and self-confidence will also be considered;

- during training, special attention will be given to restoring the body by giving recovery breaks in close relation to the objectives set.

I consider that a major role in getting the performances have specialists in the field who need a thorough training, imagination, flexibility and adaptability to the specific situations arising in training programs. 


\section{REFERENCES}

Dragnea, A. \& Mate-Teodorescu, S. (2002). Teoria sportului. Bucureşti: Fest.

Dragnea, A. (1989). Teoria antrenamentului sportiv, Partea 1. București: I.E.F.S.

Siclovan, I. (1977). Teoria antrenamentului sportiv. Bucureşti: Sport-Turism.

Mogoş, A. \& Mitra, Gh., (1980). Dezvoltarea calităţilor motrice. Bucureşti: Sport-Turism. 